\title{
Does political orientation affect happiness? The case of South Korea
}

\begin{abstract}
It is well known that in the US, conservatives are happier than liberals. The first empirical evidence for such a happiness gap between the two political groups was presented in 2006, and many subsequent studies have confirmed the finding consistently. In this study, we investigated whether a similar finding can be observed in the case of the Republic of Korea. We attempted to make a statistical estimation of the effect of political orientation on happiness using a dataset called 'Seoul Survey', which provides information on the happiness and political orientation of about 46000 citizens living in Seoul, the capital of the Republic of Korea. By controlling for all relevant socio-economic characteristics of each individual in the survey dataset, we found that political orientation has a significant effect on the level of subjective well-being or happiness. In contrast to the results observed in the US, our regression results indicated that liberals are significantly happier than conservatives. We also attempted to interpret the happiness gap in terms of monetary value.
\end{abstract}

Keywords: political orientation; conservative; liberal; happiness; subjective well-being.

JEL classification: C13; C21.

\section{Introduction}

$\bigcirc$ ubjective well-being (SWB) has been one of the most important topics in the field of psychology for decades (Diener et al., 1999). Since Easterlin's (1974) report of the non-significant relationship between SWB and aggregate income in the time-series analysis (known as the Easterlin paradox), an increasing number of economists have turned to the area of happiness to explain the Easterlin paradox. The validity of the Easterlin paradox has been debated for long (see, for example, (Deaton, 2008; Di Tella et al., 2010; Layard, 2005; Stevenson, Wolfers, 2008)), but the general consensus is that the relationship between SWB and income is clearly positive when income is low (such as in poorer nations or regions). However, this significant positive relationship tends to dissipate as the level of income reaches a critical range such as around 30000-35000 US dollars. A recent study by Proto and Rustichini (2014) reported that the relationship even becomes negative once the income exceeds the critical range. For these reasons, many countries in the recent years have attempted to develop SWB measures as a supplementary instrument for policy.

The seminal finding of Taylor et al. (2006) has prompted a very interesting research agenda on the relationship between political orientation and the degree of SWB (or happiness). Based

1 Kim, Yunmi - University of Seoul, Seoul, Republic of Korea; kimy@uos.ac.kr.

Lee, Sang-Wook - Yonsei University, Seoul, Republic of Korea; sw182496@yonsei.ac.kr.

Kim, Tae-Hwan — Yonsei University, Seoul, Republic of Korea; tae-hwan.kim@yonsei.ac.kr. 
on a 2006 public-opinion survey, Taylor et al. (2006) reported that since 1972, Republicans in the US have been more likely to report being 'very happy' than Democrats. The exact percentages are $47 \%$ for Republicans and 28\% for Democrats. Since this report, several similar findings have shown that Republicans are happier than Democrats (see, for example, (Burton et al., 2015; Jetten et al., 2013; Napier, Jost, 2008; Onraet et al., 2013; Schlenker et al., 2012; Wojcik et al., 2015)).

Researchers have attempted to use different measures of political orientation as well as of SWB; however, the findings have been consistent despite the use of different measures. In this study, we investigated whether a similar finding can be observed in the case of the Republic of Korea. The hypothesis that conservatives are happier than liberals was tested using a dataset called the 'Seoul Survey', which provides information on (i) the SWB and (ii) political orientation of about 46000 citizens living in Seoul, the capital of the Republic of Korea. We also controlled for all relevant socio-economic characteristics of each individual in the survey dataset. We believe that our study makes a significant contribution to the literature because our findings are unique in comparison to the studies conducted in the US, from an Asian viewpoint. Moreover, to the best of our knowledge, this study is the first to investigate an association between political orientation and subjective well-being in Korea.

We found that political orientation has a significant effect on the level of SWB or happiness. In contrast to the results observed in the US, our regression results showed that when all the control variables, such as income, age, gender, household size, education, job status and type, residential area, marital status, religion are held constant, liberals are significantly happier than conservatives. We also attempted to interpret the happiness gap in terms of monetary value.

The remainder of this paper is organized as follows. Section 2 describes our data. The main empirical analysis of this study is presented in Section 3. We explain why liberals are happier than conservatives in Section 4, and Section 5 provides some concluding remarks.

\section{Data description}

In this paper, we use a reported SWB indicator as a proxy to reveal the degree of happiness following the happiness literature. This variable was taken from 'Seoul Survey', which was carried out in 2013 and 2014. Both surveys contain data on 47384 and 45496 Seoul residents (aged over 15 years), respectively. The survey included a question on the degree of the SWB of the respondent. Specifically, the survey asked, 'To what extent do you feel happy?' The response was made on a scale from 100 (extremely happy) to 0 (extremely unhappy). Hence, this variable is continuous whose value is between 0 and 100. More detailed information can be obtained from the Seoul Metropolitan Government ${ }^{2}$.

2 Seoul is the capital city of South Korea, and is a municipality. Its current population is about 10 millions. The Seoul Metropolitan Government carries out the survey called 'Seoul Survey' every year in October in order to propose good policies to improve the living and environmental conditions for the city. Around 50 questions regarding important aspects of the Seoul citizens such as safety, social capital, water \& sewage, city transportation, community activities and life satisfaction are asked in the survey. Although the survey has been carried out from 2005 through 2018, we analyze the survey data from 2013 and 2014 in this paper because the key question 'To what extent do you feel happy?' has been asked in the two years only. All the survey data including questionnaires, code books and coding results can be downloaded from the following website: http://data.si.re.kr/node/523. 
The sample means of the SWB index are 73.0 and 72.7 in 2013 and 2014, respectively while the sample standard deviations are 12.0 and 11.89 in each year. To provide the whole distribution of the SWB index, we draw a histogram of the index, which is shown in Figure 1 . Such a histogram can be also converted into a proper probability density function called 'smoothed and normalized histogram', by applying the standard kernel estimation method. The smoothed and normalized histogram is provided in Figure 2 which indicates that the distribution is a little bit skewed to the left, indicating that there are some people with very low degrees of happiness.

One of the key independent variables is the political orientation of the respondents. Table 1 shows the distribution (in terms of percentage) of political groups for each survey year. In 2013, the proportions of 'conservative', 'moderate', and 'liberal' were 33, 41, and 26\%, respectively. However, in the following year, the proportion of 'liberal' significantly increased by nearly $13 \% \mathrm{p}$ while the proportion of 'moderate' reduced by a similar margin. On the contrary, the proportion of 'conservative' did not seem to change much. As a result, the proportions of 'conservative', 'moderate', and 'liberal', were 31, 30, and 39\%, respectively. Such a seemingly large shift to 'liberal' did not turn out to be temporary. Since 2014, the proportions of the three political groups have tended to stay that way. For example, the proportions were 31, 30, and 39\% in 2015, respectively, and 31,30, and 39\% in 2016, respectively, as well. It seems that in 2014, there was a structural break in the political orientation of the Republic of Korea. Due to such a sample problem, the estimation results for the two years 2013 and 2014 may not be directly comparable. It would be interesting to investigate this issue and the reason behind it; however, it is beyond the scope of this study.
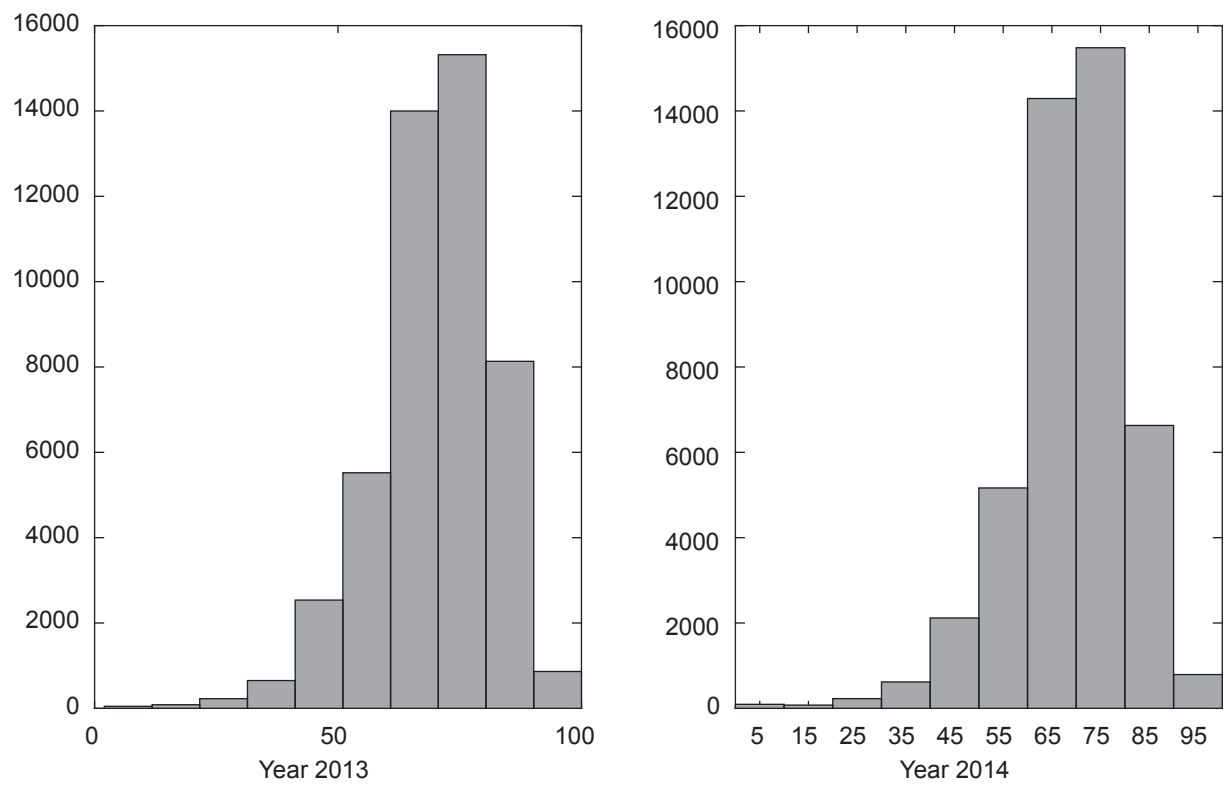

Fig. 1. Histogram of "Degree of Happiness" (based on 47384 and 45496 observations in 2013 and 2014, respectively) 


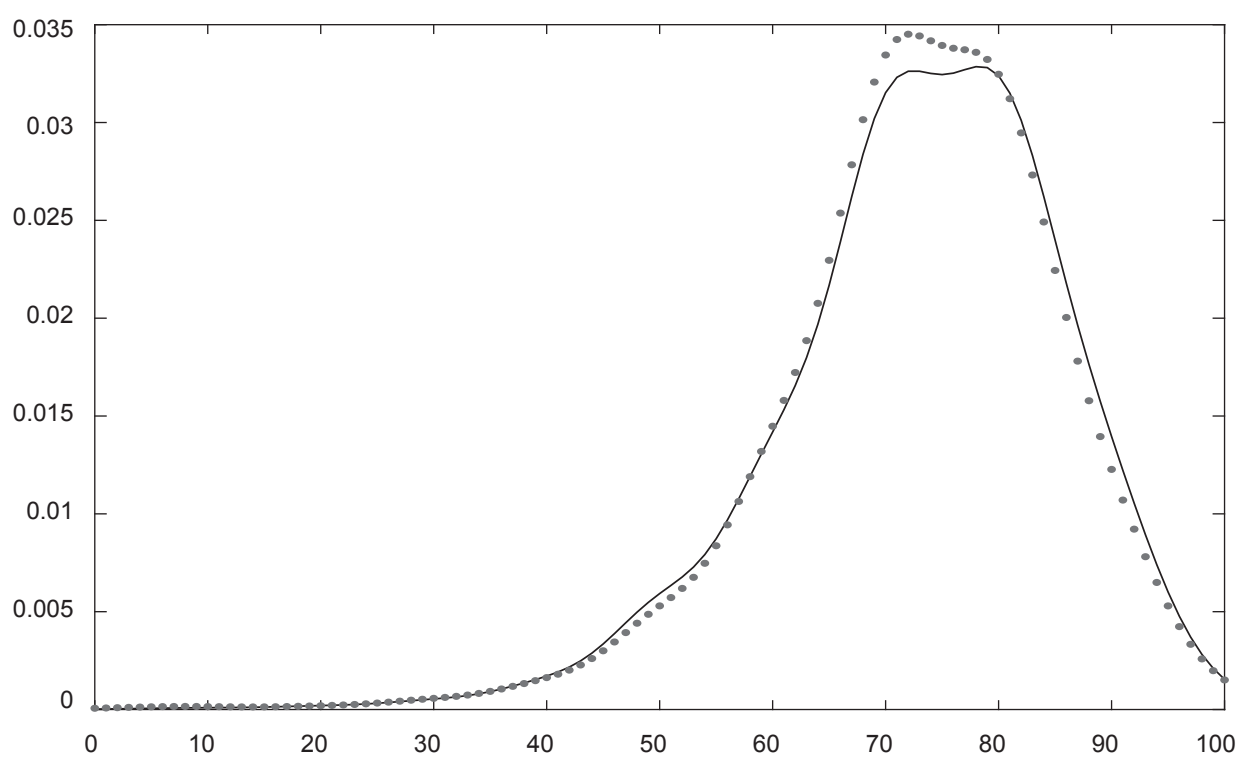

Fig. 2. Smoothed and normalized histogram of "Degree of Happiness" using the kernel density estimation method (solid line for 2013, dotted line for 2014)

Table 1. Distribution of Political Groups (in terms of percentage)

\begin{tabular}{cccc}
\hline Year & Conservative & Moderate & Liberal \\
\hline 2013 & 0.33 & 0.41 & 0.26 \\
2014 & 0.31 & 0.30 & 0.39 \\
2015 & 0.31 & 0.30 & 0.39 \\
2016 & 0.31 & 0.30 & 0.39 \\
\hline
\end{tabular}

We have carried out a simple and preliminary regression in which the dependent variable $\left(y_{i}\right)$ is the happiness index and two political dummy variables $\left(D_{M, i}\right.$ and $\left.D_{L, i}\right)$, where $D_{M, i}$ is a dummy variable taking 1 if the $i^{\text {th }}$ individual is 'moderate' and 0 otherwise; $D_{L, i}$ is another dummy variable taking 1 if the $i^{\text {th }}$ individual is 'liberal' and 0 otherwise. The regression result for 2014 is summarized as follows:

$$
\begin{gathered}
y_{i}=70.8+1.4 D_{M, i}+3.8 D_{L, i}+e_{i}, \\
(0.10)(0.14)
\end{gathered}
$$

where $e_{i}$ is the regression residual and standard errors are in parentheses. A similar result was obtained from the 2013 data. The result seems to imply that (i) liberals are happier than conservatives by 3.8 and (ii) moderates are also happier than conservatives by 1.4. However, such an interpretation is not correct because in addition to being either liberal or moderate, other factors such as income that can influence the degree of happiness - can also change the result in unknown directions. Therefore, it is impossible to identify whether the estimated increment (3.8 or 1.4) in the level of happiness is due to a specific political orientation or changes in other factors such as income. 
To identify the effect of the political orientation on happiness, we must, therefore, control for all the relevant factors that may influence happiness; this is carried out by employing multiple regression techniques, as described in the following section.

\section{Empirical analysis}

We considered the following augmented regression model accounting for all the relevant control variables:

$$
y_{i}=\alpha^{*}+\beta_{M}^{*} D_{M, i}+\beta_{L}^{*} D_{L, i}+X_{i}^{\prime} \gamma^{*}+\varepsilon_{i}
$$

where $y_{i}$ is the level of SWB (or happiness) index of the $i^{\text {th }}$ individual; $X_{i}$ is a vector of all the relevant socio-economic control variables, such as income, age, gender, household size, education, job status and type, residential area, marital status, and religion, of the $i^{\text {th }}$ individual. The key population parameter of interest is obviously $\beta_{L}^{*}$, which measures the relative effect of political orientation on SWB or happiness; that is, how much 'liberals' are happier than 'conservatives'. We call this number $\beta_{L}^{*}$ 'the degree of political happiness'.

The regression model in (1) has been estimated by the least squares method. Regression results based on the 'Seoul Survey' dataset discussed in the previous section are provided in Table 2. We have also provided some supplementary information about the estimated regression model at the end of the table, such as the overall fit of the model and White test result for heteroscedasticity.

Table 2. Baseline estimation results for 2013 and 2014

\begin{tabular}{|c|c|c|c|c|}
\hline Variable name & & & & \\
\hline Constant & $64.080 * * *$ & $(0.767)$ & $61.656 * * *$ & $(0.821)$ \\
\hline & dummies ( $b a$ & e: 'conser & & \\
\hline Moderate & 0.003 & $(0.124)$ & 0.129 & $(0.144)$ \\
\hline Liberal & $0.769 * * *$ & $(0.149)$ & $1.622 * * *$ & $(0.134)$ \\
\hline Incom & case: less th & nillion $\mathrm{Ko}$ & per month) & \\
\hline $1-2$ million & $4.774 * * *$ & $(0.566)$ & $1.723 * * *$ & $(0.586)$ \\
\hline $2-3$ million & $6.942 * * *$ & $(0.543)$ & $3.810 * * *$ & $(0.564)$ \\
\hline 3-4 million & $9.110 * * *$ & $(0.542)$ & $5.269 * * *$ & $(0.561)$ \\
\hline 4-5 million & $9.921 * * *$ & $(0.544)$ & $5.866^{* * *}$ & $(0.563)$ \\
\hline More than 5 million & $12.417 * * *$ & $(0.547)$ & $7.071 * * *$ & $(0.564)$ \\
\hline & dummies ( $b$ & se: teenag & & \\
\hline $20 \mathrm{~s}$ & $-2.556^{* * *}$ & $(0.387)$ & -0.219 & $(0.336)$ \\
\hline $30 \mathrm{~s}$ & $-4.489 * * *$ & $(0.445)$ & $-0.919 * *$ & $(0.408)$ \\
\hline $40 \mathrm{~s}$ & $-4.888 * * *$ & $(0.454)$ & $-2.530 * * *$ & $(0.417)$ \\
\hline $50 \mathrm{~s}$ & $-5.815^{* * *}$ & $(0.458)$ & $-2.719 * * *$ & $(0.422)$ \\
\hline 60 s or older & $-6.453 * * *$ & $(0.440)$ & $-2.924 * * *$ & $(0.434)$ \\
\hline & Gende & & & \\
\hline Men & $0.239^{*}$ & $(0.132)$ & $-0.486^{* * *}$ & $(0.129)$ \\
\hline
\end{tabular}


End of the Table 2

\begin{tabular}{lcccc}
\hline \multicolumn{1}{c}{ Variable name } & \multicolumn{2}{c}{ Year 2013 } & Year 2014 \\
\hline & \multicolumn{2}{c}{ Household size } & & \\
& $-0.669 * * *$ & $(0.064)$ & $-0.280 * * *$ & $(0.067)$ \\
\hline & Education & dummies (base case: elementary school) & & \\
Middle school graduates & $2.019 * * *$ & $(0.334)$ & $1.534 * * *$ & $(0.446)$ \\
High school graduates & $3.627 * * *$ & $(0.360)$ & $2.492 * * *$ & $(0.435)$ \\
Technical college students/graduates & $3.887 * * *$ & $(0.384)$ & $3.120 * * *$ & $(0.455)$ \\
College students/graduates & $4.619 * * *$ & $(0.388)$ & $3.282 * * *$ & $(0.457)$ \\
Graduate students or higher & $2.956 * * *$ & $(0.643)$ & $4.671 * * *$ & $(0.702)$ \\
\hline
\end{tabular}

Job status/type dummies (base case: unemployed)

$\begin{array}{lllll}\text { Managers/administrators } & 3.075 * * * & (0.380) & 4.997 * * * & (0.439) \\ \text { Specialists/experts } & 3.054 * * * & (0.401) & 4.528^{* * *} & (0.429) \\ \text { White collar workers } & 3.155^{* * *} & (0.317) & 3.635^{* * *} & (0.353) \\ \text { Service workers } & 0.917 * * * & (0.337) & 2.238^{* * *} & (0.360) \\ \text { Sales } & 1.740 * * * & (0.326) & 2.476^{* * *} & (0.353) \\ \text { Farmers/fishers } & 1.318 & (1.673) & 0.513 & (1.566) \\ \text { Technicians } & 1.015 * * * & (0.376) & 1.925 * * * & (0.418) \\ \text { Machine assemblers } & 0.199 & (0.506) & 2.149 * * * & (0.504) \\ \text { Temporary construction workers } & 0.939 * * & (0.439) & -0.974 * * & (0.472) \\ \text { Students } & 2.842 * * * & (0.381) & 4.026 * * * & (0.438) \\ \text { House wives } & 2.773 * * * & (0.319) & 2.786 * * * & (0.346) \\ \text { Other jobs } & 2.626 * * & (1.162) & 4.086^{* * *} & (1.512)\end{array}$

Residential area dummies (base case: central area in Seoul)

$\begin{array}{lllll}\text { North-eastern area } & -1.560 * * * & (0.219) & 0.234 & (0.198) \\ \text { North-western area } & -0.812 * * * & (0.248) & 1.406 * * * & (0.229) \\ \text { South-western area } & -0.723 * * * & (0.216) & 0.750 * * * & (0.203) \\ \text { South-eastern area } & -0.129 & (0.224) & 3.852 * * * & (0.207)\end{array}$

\begin{tabular}{|c|c|c|c|c|}
\hline \multicolumn{5}{|c|}{ Marital status dummies (base case: not married) } \\
\hline Married & $1.244 * * *$ & $(0.216)$ & $1.556 * * *$ & $(0.217)$ \\
\hline Divorced/separated & $-3.247 * * *$ & $(0.400)$ & $-3.109 * * *$ & $(0.438)$ \\
\hline Bereaved & $-2.584 * * *$ & $(0.377)$ & $-1.587 * * *$ & $(0.388)$ \\
\hline \multicolumn{5}{|c|}{ Religion dummies (base case: no religion) } \\
\hline Protestantism & $0.262 * *$ & $(0.122)$ & $0.462 * * *$ & $(0.124)$ \\
\hline Buddhism & $0.669 * * *$ & $(0.186)$ & -0.096 & $(0.192)$ \\
\hline Catholic & $1.252 * * *$ & $(0.160)$ & $0.322 *$ & $(0.171)$ \\
\hline Confucianism & $4.247 * * *$ & $(0.705)$ & 0.075 & $(1.437)$ \\
\hline Other religions & 2.530 & $(1.845)$ & -0.885 & (3.057) \\
\hline
\end{tabular}

Notes. (i) Adjusted $R^{2}$ is 0.127 for 2013 and 0.116 for 2014.

(ii) White's heteroscedasticity test results: LM statistic $=2785$ and $p$-value $<0.001$ for 2013 and LM statistic $=2768$ and $p$-value $<0.001$ for 2014 .

(iii) One US dollar is equivalent to 1129 Korean won as of July 16, 2018.

(iv) $* * *, * *, *$ represent significance at 1,5 and 10 percent levels, respectively.

(v) Robust standard errors are in parentheses. 
For example, in 2013, the adjusted $R^{2}$ is 0.127 . Hence, about $13 \%$ of the total variation of the happiness index can be explained by the estimated model. The LM statistic for the White's test is 2785 with a $p$-value virtually close to 0 , which implies the presence of heteroscedasticity. Therefore, the usual standard errors are not valid. The correct standard errors are computed by heteroscedasticity-robust covariance matrix proposed by White (1980), which we used for all the subsequent regression results.

\subsection{The effect of political orientation on happiness}

It turns out that whether one is liberal or conservative has a significant effect on the level of SWB or happiness. The estimated coefficient of $\beta_{L}^{*}$ is 0.769 in 2013, and its $t$-statistic based on the heteroscedasticity-robust standard error $(0.149)$ is 5.161 , meaning that the liberal dummy is highly significant. More specifically, when all the control variables, such as income, age, gender, household size, education, job status and type, residential area, marital status, religion are constant, just being a liberal could increase happiness by 0.769 compared to being a conservative. The result becomes even more conspicuous when looking at the data from 2014. The estimated coefficient, which is highly significant, is 1.622; this means that liberals are happier than conservatives by 1.622 . These estimated coefficients of 0.769 and 1.622 seem to be fairly small compared to the scale of the index, which takes any value between 0 and 100 . We later return to the issue of how small these values are and how to interpret them.

The other political dummy variable 'moderate' is not statistically significant in both years. The estimated values for $\beta_{M}^{*}$ are 0.003 and 0.129 in 2013 and 2014, respectively, and their $p$-values are fairly large. Hence, being conservative or moderate does not make any difference in terms of happiness.

\subsection{The effect of the other control variables on happiness}

As shown in Table 2, the regression results for 2013 and 2014 are qualitatively similar; we focus on the 2014 results to explain the effect of other control variables on happiness. The regression results show that people tend to be happier as their income increases. Specifically, if we move to the group that earns ' $1-2$ million' Korean won from the base case of 'less than 1 million', happiness increases by 1.723 . When we move to the upper levels of '2-3 million', '3-4 million', '4-5 million', and 'more than 5 million', happiness increases by $2.087,1.459,0.597$, and 1.205, respectively. The average of these marginal increments is about 1.414; thus, it could be stated that when all other variables except income are held constant, a one-million increase in income can increase happiness by about 1.414 .

When all other factors are held constant, getting old is likely to reduce happiness gradually. People in their twenties are as happy as when they are teenagers. However, when they move to their '30s', '40s', '50s', and '60s or older', their happiness reduces by $0.700,1.611,0.189$, and 0.205 , respectively. The highest fall is observed for those who entered their 40s.

It is interesting that when all the other factors in our model are held constant, men are unhappier than women by 0.486 . Considering our previous observation that when all the other variables except income are held constant, a one-million increment in income can boost happiness 
by 1.414 , this difference of 0.486 is a fairly large gap in the happiness level between men and women. This may be because men in Seoul are usually subject to more competitive and stressful ways of living than are women in Seoul. This may also be related to the traditional Korean culture wherein men - regardless of their marital status - tend to take on the responsibilities of leading their families (i.e., their present family if they are married and future family if they are not yet married).

We now turn to the three important factors accounting for happiness: (i) education, (ii) job status and type, and (iii) marital status. The regression results of the effect of these three factors are in line with our general expectations. First, we found that the higher the educational level, the higher the level of happiness. Second, people are generally happier when they are employed than when they are unemployed ${ }^{3}$; temporary construction work is the only exception to this observation. The specific job types leading to the highest levels of happiness are managers, administrators, specialists, and experts. Third, married people are happier than unmarried people; however, those who are 'divorced/separated' or 'bereaved' are unhappier than unmarried people. It should be, however, noted that when we consider the effect of these three variables, especially education, on happiness, it is possible that the issue of endogeneity might arise. Because of the absence of instrumental variables for these variable, further analysis such instrumental variable regression or two-stage regression has not been pursued. Therefore, the results should be interpreted cautiously ${ }^{4}$.

Finally, we turn to the effect of religion on happiness. Protestants are happier than those without any religion, and the happiness gap is 0.462 . Other religions such as Buddhism or Catholicism did not seem to have any significant effect on happiness. However, this is slightly different in 2013. Not only Protestants but also those who followed Buddhism, Catholicism, or Confucianism are happier than atheists.

\subsection{Checking robustness for gender gap}

In the previous regression results, it is assumed that all the marginal effects not only of the political dummy variables but also other socio-economic control variables are the same for both male and female respondents. It is possible that we can observe gender gap in some of marginal effects discussed in the previous sections. Therefore some previous results can be simply representing the mixed effects of different genders. In such a case, the results of the current model based on the common sample can be misleading. In order to check for robustness for gender

3 It is noted that the term 'unemployed' does not meet the definition of unemployment by the International Labour Organization. According to the questionnaire used in the survey, if the respondent does not have a job regardless of his/her willingness to work, he/she is classified as 'unemployed.' Therefore, the group of the 'unemployed' in the survey includes out-of-labour-force workers.

4 We note that education is usually a good predictor for both professional job status and income. Hence, only one of these variables can be included in our regression as an explanatory variable. Nonetheless, we have included all these three variables because (i) doing so improves the explanatory power of the regression model measured by the adjusted R-square (not the usual R-square) and (ii) the results from our baseline regression model are almost the same as the results from those regression models in which we exclude either education dummies or job type dummies. Those additional regression results are available from the corresponding author upon request. 
gap, we have carried out separate regressions for male and female respondents in both sample years 2013 and 2014. The numbers of male and female respondents are 22745 and 24639 in year 2013, and for the year of 2014, the corresponding numbers are 21671 and 23825. The results of the separate regressions for male and female respondents in the year of 2013 are reported in Table 3, and the corresponding results for the year of 2014 are shown in Table 4.

Table 3. Estimation results for 2013 based on gender

\begin{tabular}{lcccc}
\hline \multirow{2}{*}{ Variable name } & \multicolumn{2}{c}{ Male } & \multicolumn{2}{c}{ Female } \\
& (number of respondents $=22745)$ & \multicolumn{2}{c}{ (number of respondents = 24639) } \\
\hline Constant & $63.753^{* * *}$ & $(1.154)$ & $63.838^{* * *}$ & $(1.081)$ \\
\hline & Political dummies & (base case: 'conservative') & \\
Moderate & -0.215 & $(0.175)$ & 0.165 & $(0.176)$ \\
Liberal & $0.698^{* * *}$ & $(0.211)$ & $0.812^{* * *}$ & $(0.210)$ \\
\hline
\end{tabular}

\begin{tabular}{|c|c|c|c|c|}
\hline \multicolumn{5}{|c|}{ Income dummies (base case: less than 1 million Korean won per month) } \\
\hline 1-2 million & $5.439 * * *$ & $(0.916)$ & $4.278^{* * *}$ & $(0.723)$ \\
\hline $2-3$ million & $7.815^{* * *}$ & $(0.873)$ & $6.475^{* * *}$ & $(0.697)$ \\
\hline 3-4 million & $10.265 * * *$ & $(0.866)$ & $8.332 * * *$ & $(0.699)$ \\
\hline 4-5 million & $11.397 * * *$ & $(0.868)$ & $8.830 * * *$ & $(0.704)$ \\
\hline More than 5 million & $13.602 * * *$ & $(0.873)$ & $11.576^{* * *}$ & $(0.709)$ \\
\hline \multicolumn{5}{|c|}{ Age dummies (base case: teenage) } \\
\hline $20 \mathrm{~s}$ & $-2.997 * * *$ & $(0.565)$ & $-1.959 * * *$ & $(0.544)$ \\
\hline $30 \mathrm{~s}$ & $-4.609 * * *$ & $(0.654)$ & $-3.970 * * *$ & $(0.626)$ \\
\hline $40 \mathrm{~s}$ & $-5.406^{* * *}$ & $(0.670)$ & $-4.058 * * *$ & $(0.635)$ \\
\hline $50 \mathrm{~s}$ & $-6.433^{* * *}$ & $(0.676)$ & $-4.904 * * *$ & $(0.639)$ \\
\hline 60 s or older & $-6.421 * * *$ & $(0.665)$ & $-6.320 * * *$ & $(0.606)$ \\
\hline \multicolumn{5}{|c|}{ Household size } \\
\hline & $-0.606 * * *$ & $(0.092)$ & $-0.684 * * *$ & $(0.092)$ \\
\hline \multicolumn{5}{|c|}{ Education dummies (base case: elementary school) } \\
\hline Middle school graduates & $1.741 * * *$ & $(0.542)$ & $1.940 * * *$ & $(0.431)$ \\
\hline High school graduates & $3.319 * * *$ & $(0.583)$ & $3.376^{* * *}$ & $(0.479)$ \\
\hline $\begin{array}{l}\text { Technical college students/ } \\
\text { graduates }\end{array}$ & $3.647 * * *$ & $(0.610)$ & $3.665^{* * *}$ & $(0.517)$ \\
\hline College students/graduates & $4.646^{* * *}$ & $(0.611)$ & $4.100 * * *$ & $(0.527)$ \\
\hline Graduate students or higher & $2.869 * * *$ & $(0.840)$ & $2.560^{* *}$ & (1.219) \\
\hline
\end{tabular}

Job status/type dummies (base case: unemployed)

$\begin{array}{lllll}\text { Managers/administrators } & 2.862^{* * *} & (0.469) & 2.328^{* *} & (0.950) \\ \text { Specialists/experts } & 2.724 * * * & (0.515) & 3.769^{* * *} & (0.735) \\ \text { White collar workers } & 2.550^{* * *} & (0.433) & 4.332^{* * *} & (0.546) \\ \text { Service workers } & 0.316 & (0.451) & 2.133^{* * *} & (0.575) \\ \text { Sales } & 1.185^{* * *} & (0.431) & 2.846^{* * *} & (0.561) \\ \text { Farmers/fishers } & 0.088 & (2.040) & 6.124 * * * & (1.591) \\ \text { Technicians } & 1.062^{* *} & (0.460) & -0.180 & (0.823) \\ \text { Machine assemblers } & 0.260 & (0.584) & -3.374 * * & (1.414)\end{array}$


End of the Table 3

\begin{tabular}{|c|c|c|c|c|}
\hline Variable name & \multicolumn{2}{|c|}{$\begin{array}{c}\text { Male } \\
(\text { number of respondents }=22745)\end{array}$} & \multicolumn{2}{|c|}{$\begin{array}{c}\text { Female } \\
(\text { number of respondents }=24639)\end{array}$} \\
\hline Temporary construction workers & 0.548 & $(0.538)$ & $1.779 * *$ & $(0.767)$ \\
\hline Students & $2.234 * * *$ & $(0.536)$ & $3.976 * * *$ & $(0.612)$ \\
\hline House wives & 2.628 & $(2.184)$ & $3.851 * * *$ & $(0.531)$ \\
\hline Other jobs & $2.327 *$ & $(1.362)$ & 3.402 & $(2.211)$ \\
\hline \multicolumn{5}{|c|}{ Residential area dummies (base case: central area in Seoul) } \\
\hline North-eastern area & $-1.336^{* * *}$ & $(0.304)$ & $-1.717 * * *$ & $(0.315)$ \\
\hline North-western area & $-0.878^{* *}$ & $(0.345)$ & $-0.703 * *$ & $(0.356)$ \\
\hline South-western area & $-0.692 * *$ & $(0.299)$ & $-0.727 * *$ & $(0.310)$ \\
\hline South-eastern area & -0.298 & $(0.312)$ & 0.073 & $(0.321)$ \\
\hline \multicolumn{5}{|c|}{ Marital status dummies (base case: not married) } \\
\hline Married & $1.423 * * *$ & $(0.309)$ & $0.827 * * *$ & $(0.314)$ \\
\hline Divorced/separated & $-2.780 * * *$ & $(0.665)$ & $-3.779 * * *$ & $(0.516)$ \\
\hline Bereaved & $-1.502 * *$ & $(0.653)$ & $-2.889 * * *$ & $(0.493)$ \\
\hline \multicolumn{5}{|c|}{ Religion dummies (base case: no religion) } \\
\hline Protestantism & 0.248 & $(0.172)$ & 0.278 & $(0.173)$ \\
\hline Buddhism & $0.955 * * *$ & $(0.269)$ & $0.486^{*}$ & $(0.256)$ \\
\hline Catholic & $1.294 * * *$ & $(0.234)$ & $1.230 * * *$ & $(0.220)$ \\
\hline Confucianism & $3.217 * * *$ & $(1.016)$ & $5.005 * * *$ & $(0.969)$ \\
\hline Other religions & 1.309 & $(2.456)$ & 3.670 & $(2.761)$ \\
\hline
\end{tabular}

Notes. (i) Adjusted $R^{2}$ is 0.116 for 2013 male and 0.139 for 2013 female.

(ii) White's heteroscedasticity test results: LM statistic $=1671$ and $p$-value $<0.001$ for 2013 male and LM statistic $=1826$ and $p$-value $<0.001$ for 2013 female.

(iii) One US dollar is equivalent to 1129 Korean won as of July 16, 2018.

(iv) $* * *, * *, *$ represent significance at 1,5 and 10 percent levels, respectively.

(v) Robust standard errors are in parentheses.

Table 4. Estimation results for 2014 based on gender

\begin{tabular}{|c|c|c|c|c|}
\hline Variable name & \multicolumn{2}{|c|}{$\begin{array}{c}\text { Male } \\
\text { (number of respondents }=21671 \text { ) }\end{array}$} & \multicolumn{2}{|c|}{$\begin{array}{c}\text { Female } \\
(\text { number of respondents }=23825)\end{array}$} \\
\hline Constant & $60.275^{* * *}$ & $(1.338)$ & $63.447 * * *$ & $(1.105)$ \\
\hline \multicolumn{5}{|c|}{ Political dummies (base case: 'conservative') } \\
\hline Moderate & -0.161 & $(0.206)$ & $0.398 * *$ & $(0.201)$ \\
\hline Liberal & $1.085 * * *$ & $(0.193)$ & $2.126 * * *$ & $(0.187)$ \\
\hline \multicolumn{5}{|c|}{ Income dummies (base case: less than 1 million Korean won per month) } \\
\hline 1-2 million & $1.696^{*}$ & $(0.986)$ & $1.556^{* *}$ & $(0.726)$ \\
\hline 2-3 million & $4.247 * * *$ & $(0.945)$ & $3.222 * * *$ & $(0.706)$ \\
\hline 3-4 million & $5.948 * * *$ & $(0.940)$ & $4.506 * * *$ & $(0.702)$ \\
\hline 4-5 million & $6.539 * * *$ & $(0.941)$ & $5.116 * * *$ & $(0.707)$ \\
\hline More than 5 million & $8.007 * * *$ & $(0.941)$ & $6.047 * * *$ & $(0.711)$ \\
\hline
\end{tabular}


Continued Table 4

\begin{tabular}{|c|c|c|c|c|}
\hline \multirow[t]{2}{*}{ Variable name } & \multicolumn{2}{|c|}{$\begin{array}{c}\text { Male } \\
(\text { number of respondents }=21671)\end{array}$} & \multicolumn{2}{|c|}{$\begin{array}{c}\text { Female } \\
(\text { number of respondents }=23825)\end{array}$} \\
\hline & \multicolumn{4}{|c|}{ Age dummies (base case: teenage) } \\
\hline $20 \mathrm{~s}$ & 0.523 & $(0.499)$ & -0.746 & $(0.461)$ \\
\hline $30 \mathrm{~s}$ & -0.087 & $(0.620)$ & $-1.466 * * *$ & $(0.552)$ \\
\hline $40 \mathrm{~s}$ & $-2.318 * * *$ & $(0.637)$ & $-2.494 * * *$ & $(0.560)$ \\
\hline $50 \mathrm{~s}$ & $-2.694 * * *$ & $(0.643)$ & $-2.489 * * *$ & $(0.567)$ \\
\hline 60 s or older & $-2.493 * * *$ & $(0.660)$ & $-3.130 * * *$ & $(0.584)$ \\
\hline \multicolumn{5}{|c|}{ Household size } \\
\hline & $-0.310 * * *$ & $(0.099)$ & $-0.273 * * *$ & $(0.092)$ \\
\hline \multicolumn{5}{|c|}{ Education dummies (base case: elementary school) } \\
\hline Middle school graduates & 1.186 & $(0.838)$ & $1.730 * * *$ & $(0.531)$ \\
\hline High school graduates & 1.326 & $(0.812)$ & $3.225 * * *$ & $(0.526)$ \\
\hline $\begin{array}{l}\text { Technical college students/ } \\
\text { graduates }\end{array}$ & $1.832 * *$ & $(0.831)$ & $3.992 * * *$ & $(0.559)$ \\
\hline College students/graduates & $1.998^{* *}$ & $(0.834)$ & $4.123 * * *$ & $(0.562)$ \\
\hline Graduate students or higher & $4.041 * * *$ & $(1.041)$ & $3.988 * * *$ & $(1.153)$ \\
\hline
\end{tabular}

Job status/type dummies (base case: unemployed)

$\begin{array}{lllll}\text { Managers/administrators } & 5.815 * * * & (0.545) & 3.311 * * * & (1.043) \\ \text { Specialists/experts } & 5.177 * * * & (0.549) & 3.604 * * * & (0.802) \\ \text { White collar workers } & 4.385 * * * & (0.486) & 2.362 * * * & (0.574) \\ \text { Service workers } & 3.431 * * * & (0.493) & 0.494 & (0.574) \\ \text { Sales } & 3.172 * * * & (0.476) & 1.213 * * & (0.568) \\ \text { Farmers/fishers } & 2.599 & (1.707) & -6.368 * & (3.625) \\ \text { Technicians } & 2.652 * * * & (0.524) & 1.029 & (0.806) \\ \text { Machine assemblers } & 3.354 * * * & (0.597) & -2.723 * * & (1.329) \\ \text { Temporary construction Workers } & 0.208 & (0.635) & -2.726 * * * & (0.722) \\ \text { Students } & 5.358 * * * & (0.617) & 2.273 * * * & (0.674) \\ \text { House wives } & -17.497 & (15.87) & 1.641 * * * & (0.537) \\ \text { Other jobs } & 2.746 & (2.439) & 4.822 * * * & (1.798)\end{array}$

Other jobs

Residential area dummies (base case: central area in Seoul)

\begin{tabular}{lllll} 
North-eastern area & 0.293 & $(0.284)$ & 0.205 & $(0.275)$ \\
North-western area & $1.359 * * *$ & $(0.328)$ & $1.459 * * *$ & $(0.318)$ \\
South-western area & $0.580 * *$ & $(0.295)$ & $0.920 * * *$ & $(0.281)$ \\
South-eastern area & $3.779 * * *$ & $(0.300)$ & $3.935 * * *$ & $(0.285)$ \\
\hline
\end{tabular}

South-eastern area

Marital status dummies (base case: not married)

\begin{tabular}{lllll} 
Married & $2.143 * * *$ & $(0.313)$ & $0.958 * * *$ & $(0.306)$ \\
Divorced/separated & $-4.340 * * *$ & $(0.801)$ & $-2.742 * * *$ & $(0.527)$ \\
Bereaved & $-1.503 * *$ & $(0.713)$ & $-2.051 * * *$ & $(0.498)$ \\
\hline \multicolumn{4}{l}{ Religion dummies } & (base case: no religion) \\
Protestantism & $0.892 * * *$ & $(0.180)$ & 0.035 & $(0.172)$ \\
Buddhism & $0.553 * *$ & $(0.274)$ & $-0.676 * *$ & $(0.268)$ \\
Catholic & $0.446 *$ & $(0.259)$ & 0.155 & $(0.227)$
\end{tabular}


End of the Table 4

\begin{tabular}{lcccc}
\hline \multicolumn{1}{c}{ Variable name } & \multicolumn{2}{c}{ Male } & \multicolumn{2}{c}{$\begin{array}{c}\text { Female } \\
\text { (number of respondents = 21671) }\end{array}$} \\
\hline Confucianism & -1.504 & $(2.127)$ & 1.470 & $(1.917)$ \\
Other religions & -0.451 & $(4.635)$ & -1.418 & $(3.865)$ \\
\hline
\end{tabular}

Notes. (i) Adjusted $R^{2}$ is 0.120 for 2014 male and 0.117 for 2014 female.

(ii) White's heteroscedasticity test results: LM statistic $=1908$ and $p$-value $<0.001$ for 2014 male and LM statistic $=1822$ and $p$-value $<0.001$ for 2014 female.

(iii) One US dollar is equivalent to 1129 Korean won as of July 16, 2018.

(iv) $* * *, * * *$ represent significance at 1,5 and 10 percent levels, respectively.

(v) Robust standard errors are in parentheses.

It is evident from Tables 3 and 4 that the new estimation results for different genders are qualitatively similar to the previous results based on the whole sample. The main findings about the effects of political dummy variables are unchanged and the marginal effects of all the socioeconomic control variables are generally similar, of course, with some mild variations in terms of the absolute size of estimated coefficients and their statistical significance. As before, we focus on the 2014 results to describe the gender effects.

The estimated values for the degree of political happiness $\beta_{L}^{*}$ are 1.084 and 2.126 for male and female samples, respectively, both of which are highly significant, meaning that liberal men and women are happier than their conservative counterparts ceteris paribus. A new interesting discovery is that the degree of 'being happier than conservatives' is greater for liberal women (2.126) than for liberal men (1.804). The difference is 1.042 and, according to our additional statistical analysis, the difference is statistically different from zero with a $p$-value virtually close to 0 ( $t$-statistic based on robust standard errors is 3.874 ). The previously reported value for $\beta_{L}^{*}$ based on the whole sample is 1.622 so that it can be viewed as an average of those two numbers based on male and female samples. Another interesting finding is that, unlike the whole sample result, the political dummy variable 'moderate' for female is significant at the $5 \%$ level, implying that politically moderate women are also happier than their conservative counterparts.

As mentioned before, the marginal effects of all the socio-economic control variables based on different genders are generally similar to those based on the whole sample. Hence, we will focus on some different results compared to the whole sample results. According to the whole sample results, the degree of happiness increases monotonically with the level of education, starting from elementary school. This finding is still supported for women, but not for men. For the male respondents, middle school graduates and high school graduates are not different from elementary school graduates. The whole sample regression shows that people are generally happier when they are employed than when they are unemployed with the only exception being temporary construction workers. The gender regression adds one more job 'machine assembler' to this list; female machine assemblers are even unhappier than unemployed.

\subsection{Interpreting the degree of political happiness}

It was shown above that when all the other factors in our model are held constant, liberals are happier than conservatives by the margin of 0.769 in 2013 and 1.622 in 2014 . However, it could be argued that a margin of 0.769 or 1.622 on a scale from 0 to 100 is not significant. 
We now turn to the issue of how to interpret these seemingly infinitesimal values, the degree of political happiness.

When we investigate the effect of income on happiness, it is observed that when all other variables except income are held constant, an increment of one million Korean won in income could increase happiness by 2.483 on average in 2013. In other words, the number 2.483 is the average of the marginal effects of income on SWB. A similar calculation shows that the corresponding number is 1.414 in 2014; that is, an increment of one million Korean won in income could increase happiness by 1.414 on average in 2014. Based on this relationship between income and happiness, it is possible to calculate how much income is required to increase the level of happiness by 0.769 or 1.622 . A simple calculation can show that an increment of 310000 Korean won (equivalent to 270 US dollars) per month can increase the level of happiness by 0.769 in the year of 2013. In 2014, an additional 1150000 Korean won (equivalent to 1020 US dollars) per month is needed to increase happiness by 1.622 . Therefore, a possible interpretation is that the monetary value of being liberal rather than being conservative is approximately equivalent to earning an additional 270 US dollars per month in 2013 (and an additional 1020 US dollars per month in 2014) $)^{5}$.

It should be noted that the calculation and interpretation above is based on only the average of the marginal effects of income on SWB. Therefore, the calculated numbers should not be literally taken as real money values. They are provided only to convey some rough ideas on those seemingly very small estimates of the political dummy variables.

\section{Why are liberals happier than conservatives?}

The regression results in the previous section show that liberals are significantly happier than conservatives in the Republic of Korea. Naturally, one might ask why. Although answering this is beyond the scope of this study, we will attempt to provide some partial answers, given the limitations of the data used in the analysis.

First, we will describe the limitations of the data used in this study. We could have characterized the three political groups (i.e., conservative, moderate, and liberal) by the variables used in the regression analysis, such as income or education. For example, Tables 5a, $5 \mathrm{~b}$ report the distribution of income for the entire sample (denoted 'population') as well as the three political groups in each year. It can be observed from the tables that liberals earn a higher income than conservatives. For example, for the highest income category 'more than 5 million', 33\% of liberals belong to this group, whereas only $28 \%$ of conservatives belong. On the contrary, there are more conservatives than liberals in the lowest income bracket 'less than 1 million'.

5 All the calculations above are based on the averaged values (2.483 and 1.4142 for 2013 and 2014, respectively) of the marginal effects of income on SWB. When carefully examining those marginal effects, one can notice that the marginal effect of the control group (i.e., the group whose monthly income is less than 1 million Korean won) is large, especially in 2013. Hence, it can be informative to carry out additional calculations without such a large effect. When excluding the control group, the averaged marginal values of income on SWB are 1.911 and 1.337 for 2013 and 2014 , respectively. Consequently, the monetary values of the degree of political happiness are approximately 400000 Korean won (equivalent to 350 US dollars) for 2013 and 1200000 Korean won (equivalent to 1070 US dollars). 
Table 5a. Distribution of income in 2013

\begin{tabular}{lcccc}
\hline \multicolumn{1}{c}{ Income range } & Population & Conservative & Moderate & Liberal \\
\hline Less than 1 million & 0.02 & 0.03 & 0.02 & 0.01 \\
1-2 million & 0.06 & 0.08 & 0.05 & 0.04 \\
2-3 million & 0.13 & 0.15 & 0.13 & 0.12 \\
3-4 million & 0.27 & 0.25 & 0.28 & 0.28 \\
4-5 million & 0.24 & 0.23 & 0.25 & 0.25 \\
More than 5 million & 0.28 & 0.26 & 0.27 & 0.30 \\
\hline
\end{tabular}

Table 5b. Distribution of income in 2014

\begin{tabular}{lcccc}
\hline \multicolumn{1}{c}{ Income range } & Population & Conservative & Moderate & Liberal \\
\hline Less than 1 million & 0.02 & 0.04 & 0.02 & 0.01 \\
1-2 million & 0.06 & 0.09 & 0.05 & 0.04 \\
2-3 million & 0.12 & 0.14 & 0.12 & 0.11 \\
3-4 million & 0.24 & 0.22 & 0.25 & 0.24 \\
4-5 million & 0.25 & 0.23 & 0.25 & 0.27 \\
More than 5 million & 0.31 & 0.28 & 0.31 & 0.33 \\
\hline
\end{tabular}

Table 5c. Distribution of education in 2013

\begin{tabular}{lcccc}
\hline \multicolumn{1}{c}{ Education } & Population & Conservative & Moderate & Liberal \\
\hline Elementary school & 0.05 & 0.07 & 0.04 & 0.03 \\
Middle school & 0.11 & 0.12 & 0.11 & 0.10 \\
High school & 0.36 & 0.42 & 0.36 & 0.28 \\
Technical college & 0.23 & 0.20 & 0.23 & 0.26 \\
College & 0.24 & 0.18 & 0.25 & 0.31 \\
Graduate school or higher & 0.01 & 0.01 & 0.01 & 0.02 \\
\hline
\end{tabular}

Table 5d. Distribution of education in 2014

\begin{tabular}{lcccc}
\hline \multicolumn{1}{c}{ Education } & Population & Conservative & Moderate & Liberal \\
\hline Elementary school & 0.03 & 0.02 & 0.02 & 0.01 \\
Middle school & 0.09 & 0.08 & 0.07 & 0.07 \\
High school & 0.35 & 0.37 & 0.32 & 0.28 \\
Technical college & 0.23 & 0.25 & 0.28 & 0.25 \\
College & 0.29 & 0.27 & 0.30 & 0.37 \\
Graduate school or higher & 0.01 & 0.01 & 0.01 & 0.02 \\
\hline
\end{tabular}

The distribution of the respondents by education is shown in Tables $5 \mathrm{c}, 5 \mathrm{~d}$, which indicates that liberals tend to acquire much higher education than conservatives; for example, $37 \%$ of liberals have a college degree while only $27 \%$ of conservatives have the equivalent degree. These findings are interesting as usually the opposite is expected. However, it cannot explain why liberals are happier than conservatives since the income and education variables have been already 
included in the main regression, and therefore, they were controlled for. In other words, through the regression method, we created a condition wherein both liberals and conservatives earn the exact same income every month and have the exactly same education level.

Hence, explaining the happiness gap between the two political groups needs some information that was not included in the main regression. Helliwell (2008) demonstrated that relational ties such as marriage and voluntary activities are significantly and positively related to life satisfaction. Further, Bruni and Stanca (2008) found a strong correlation between the time spent on an activity with a relational component and self-reported SWB. Within the same dataset, we were able to obtain some information on voluntary activities. The survey included the following questions: (i) Have you ever participated in voluntary activities during the last one year? (ii) Are you willing to participate in voluntary activities in the future? The responses to these two questions are summarized in Tables 6 and 7, respectively. Table 6 shows the percentage of people in the two groups (conservative and liberal) who have never participated in voluntary activities such as environmental conservation, education, helping the disadvantaged, or culture and arts. In both 2013 and 2014, the percentages are consistently higher for conservatives than for liberals in all voluntary activities, suggesting that liberals participate in these activities more actively than do conservatives.

Table 6. Percentage of people in each political group who did not participate

\begin{tabular}{lcccc}
\hline \multirow{2}{*}{ Types of voluntary activities } & \multicolumn{2}{c}{ Year 2013 } & \multicolumn{2}{c}{ Year 2014 } \\
\cline { 2 - 5 } & Conservative & Liberal & Conservative & Liberal \\
\hline Environment conservation & 78.6 & 76.7 & 95.4 & 92.9 \\
Education & 89.0 & 86.9 & 97.6 & 94.9 \\
Helping the disadvantaged & 78.6 & 76.7 & 95.5 & 93.3 \\
Culture and arts & 78.6 & 76.7 & 98.9 & 98.1 \\
\hline
\end{tabular}

Table 7. Percentage of people in each political group who expressed willingness to participate in voluntary activities in the future

\begin{tabular}{ccccc}
\hline Response & Population & Conservative & Moderate & Liberal \\
\hline I will participate (in year 2013) & 46.1 & 41.7 & 46.8 & 50.3 \\
I will participate (in year 2014) & 51.0 & 43.7 & 52.2 & 54.8 \\
\hline
\end{tabular}

Table 7 shows the responses to the second question in 2013 and 2014 respectively. The results for 2013 indicate that substantially more liberals are willing to participate in voluntary activities in the future than conservatives are. Specifically, $50.3 \%$ of the liberals are willing to participate, whereas only $41.7 \%$ of conservatives are willing. The gap is about $9 \%$ p. Such a gap becomes even wider in 2014.

Empirical studies of SWB have found that social capital and relational goods positively affect an individual's SWB (Becchetti et al., 2008; Bruni, Porta, 2007; Bruni, Stanca, 2008; Leung et al., 2013). According to the reported statistical evidence in Tables 6 and 7, liberals in Korea seem to have more relational ties to either the society as a whole or their neighbourhood through voluntary activities. We speculate that such strong relational ties or relational 
goods possessed by liberals can partially explain why liberals tend to be happier than conservatives in Korea.

Of course, voluntary activities might only be one contributing component when assessing the relational goods as a whole. There might be many other components such as companionship, emotional support, social approval, sense of belongingness, or experiencing one's own history; these must be considered to make an accurate estimation of relational goods possessed. Moreover, not only relational goods but also social capital is a crucial determinant for SWB. We do not measure social capital in this study due to data limitations. Comprehensively characterizing both social capital and relational goods for the two political groups (liberals and conservatives) in Korea seems to be the first correct step towards understanding why liberals are happier than conservatives in Korea, which is beyond the scope of the current study and future studies should investigate this in more detail.

\section{Conclusion}

In this study, we attempted to statistically estimate the effect of political orientation on happiness using a dataset called 'Seoul Survey', which provides information on the (i) happiness and (ii) political orientation of about 46000 citizens living in Seoul, the capital of the Republic of Korea. By controlling for all relevant socio-economic characteristics of each individual in the survey dataset, we found that political orientation has a significant effect on the level of SWB or happiness. In sharp contrast to the findings observed in the US, our regression results indicated that liberals are significantly happier than conservatives. We attempted to interpret the happiness gap in terms of monetary value. According to our calculation, the monetary value of being liberal rather than being conservative is approximately equivalent to earning an additional 270 US dollars per month in 2013 (and additional 1020 US dollars per month in 2014). We also tried to partially explain why liberals are happier than conservatives in Korea. According to some statistical evidence uncovered from the dataset, liberals in Korea seem to have more relational ties to either the society as a whole or their neighbourhood through voluntary activities. We speculate that such stronger relational ties possessed by liberals might partially explain the happiness gap.

Acknowledgments. Tae-Hwan Kim is grateful for financial support from the Ministry of Education of the Republic of Korea and the National Research Foundation of Korea (NRF2017S1A5A2A01025435). Yunmi Kim acknowledges that this work was supported by the 2019 sabbatical year research grant of the University of Seoul.

\section{References}

Becchetti L., Pelloni A., Rossetti F. (2008). Relational goods, sociability, and happiness. KYKLOS, 61 (3), 343-363.

Bruni L., Porta P. (2007). Handbook on the economics of happiness. Edward Elgar Publishing Ltd., Cheltenham, UK \& Northampton, MA, USA.

Bruni L., Stanca L. (2008). Watching alone: Relational goods, television and happiness. Journal of Economic Behavior and Organization, 65, 506-528. 
Burton C. M., Plaks J. E., Peterson J. B. (2015). Why do conservatives report being happier than liberals? The contribution of neuroticism. Journal of Social and Political Psychology, 3, 89-102.

Deaton A. (2008). Income, health and well-being around the world: Evidence from the Gallup World Poll. Journal of Economic Perspectives, 22, 53-72.

Diener E., Suh E. M., Lucas R., Smith H. (1999). Subjective well-being: Three decades of progress. Psychological Bulletin, 125, 276-302.

Di Tella R., MacCulloch R. (2010). Happiness adaptation to income beyond «basic needs». In: E. Diener, J. Helliwell, D. Kahneman (eds.), International differences in well-being, 217-246. Oxford: Oxford University Press.

Easterlin R. (1974). Does economic growth improve the human lot? Some empirical evidence. In: Paul A. David, Melvin W. Reder (eds.), Nations and households in economic growth: Essays in honor of Moses Abramovitz, 89-125. New York: Academic Press, Inc.

Helliwell J. F. (2008). Life satisfaction and quality of development. NBER Working Paper No. 14507, National Bureau of Economic Research.

Jetten J., Haslam S. A., Barlow F. K. (2013). Bringing back the system: One reason why conservatives are happier than liberals is that higher socioeconomic status gives them access to more group memberships. Social Psychological and Personality Science, 4, 6-13.

Layard R. (2005). Happiness: Lessons from a new science. London: Penguin.

Leung A., Kier C., Fung T., Fung L., Sproule R. (2013). Searching for happiness: The importance of social capital. In: The exploration of happiness, 247-267. Springer Netherlands.

Napier J. L., Jost J. T. (2008). Why are conservatives happier than liberals? Psychological Science, 19, $565-572$.

Onraet E., Hiel A. V., Dhont K. (2013). The relationship between right-wing ideological attitudes and psychological well-being. Personality and Social Psychology Bulletin, 39, 509-522.

Proto E., Rustichini A. (2014). GDP and life satisfaction: New evidence. https://voxeu.org/article/gdpand-life-satisfaction-new-evidence.

Schlenker B. R., Chambers J. R., Le B. M. (2012). Conservatives are happier than liberals, but why? Political ideology, personality, and life satisfaction. Journal of Research in Personality, 46, 127-146.

Wojcik S. P., Hovasapian A., Graham J., Motyl M., Ditto P. H. (2015). Conservatives report, but liberals display, greater happiness. Science, 347, 1243-1246.

Stevenson B., Wolfers J. (2008). Economic growth and subjective well-being: Reassessing the Easterlin Paradox. Brookings Papers on Economic Activity, 1, 1-87.

Taylor P., Fund C., Craighill P. (2006). Are we happy yet? Social Trends Report. Pew Research Center. https://www.pewresearch.org/wp-content/uploads/sites/3/2010/10/AreWeHappyYet.pdf.

White H. (1980). A heteroskedasticity-consistent covariance matrix estimator and a direct test for heteroskedasticity. Econometrica, 48, 827-838.

Received 20.08.2019; accepted 11.02.2020. 